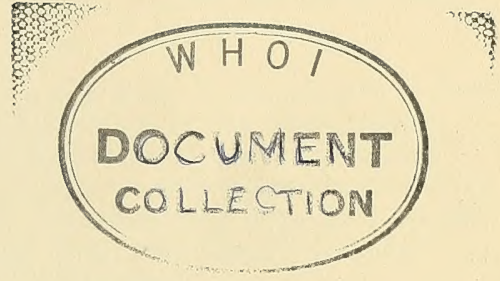

\title{
Evaluation of External Lighting Systems For The Bathyscaph TRIESTE
}

LT L. A. Shumaker, USN 



\section{THE PROBLEM}

Develop the best combination of light source and casing, compatible with the existing power supply, for observation and photography from the bathyscaph TRIESTE in the deepsea environment.

This problem was complicated by a short time period allowed due to urgent operational commitments of the bathyscaph. The work was directed toward achieving reliability under all conditions of pressure and temperature expected to exist in the deep ocean; ease of unit replacement; adequate areal lighting for visual observations; and best possible color temperature for underwater photography.

\section{RESULTS}

1. In view of the urgency in getting the bathyscaph operational, it was necessary to accept a compromise in the problem solution. While development of a lamp that will meet all the above requirements is approaching completion, the present system meets only the first three requirements, namely, reliability, ease of replacement, and adequate areal lighting for visual observations.

2. The system developed involves two types of lamps, both of which are light in weight and easily replaceable. One gives good reliability with an extremely long bulb life; the other gives good areal lighting, but has relatively short bulb life. A supplementary report will be made upon completion of development of the more nearly ideal lamp that is now in the testing stages.

\section{RECOMMENDATIONS}

1. Continue the program to improve the presently operational lighting system on the bathyscaph.

2. Complete development of a lamp that meets all of the requirements stated above. 


\section{ADMINISTRATIVE INFORMATION}

Work was performed under S-R004 0301 (NEL L4-2) by members of the Bathyscaph Project Team, Signal Propagation Division, and the Human Factors Division. The report covers work from October 1959 through December 1961 both at NEL and at Guam, M. I., and was approved for publication 21 December 1961. 


\section{CONTENTS}

\section{BACKGROUND... page 5}

DEVELOPMENT CONSIDERATIONS. . . 7

NEL (AKIN) LAMP...8

EDGERTON LAMP... 15

BUSHIPS LAMP CASING... 17

PEK LAMP. . 18

RESULTS AND DISCUSSION...19

RECOMMENDATIONS. . .22 


\section{ILLUSTRATIONS}

1 Mercury vapor lamp employed in the original lighting system on the bathyscaph...page 5

2 Mercury vapor lamps of original lighting system shown mounted in tandem as originally used on bathyscaph... 6

3 General Electric AH-6 lamp that was unsuccessfully attempted as a substitute for original mercury vapor lamp... 7

4 Construction details of NEL deep submergence lamp. . .10

5 Oblique view of assembled NEL deep submergence lamp... I1

6 Top view of NEL lamp showing single mounting hole and recessed Joy plug for $+24 \mathrm{vdc}$ connection. . . 12

7 NEL lamp with bulb, bulb mount, and back removed...13

8 Same as figure 7 with Plexiglas window and heat shield removed and showing recessed window mounting... 14

9 NEL lamp casing, tested to destruction, showing the inside surface of the window, inside of casing, and the bulb and bulb mounting... 14

10 Same lamp casing showing outside of the window, the front of the casing, and the back of the mounting plate...15

11 Edgerton lamp with reflector removed... 16

12 Edgerton lamp with reflector in place... 16

13 Disassembled BUSHIPS lamp casing. . . 17

14 Components of two BUSHIPS lamp casings after testing to destruction... 18

15 PEK Laboratories 500-watt, 24-vdc incandescent lamp, Model No. 3... I9

16 Side view of NEL lamp cluster under the bow of the bathyscaph...20

17 Bottom view of bow lamp cluster...20

18 Two five-lamp clusters of NEL lamps, amidships... 20

19 Edgerton lamp mounted on bathyscaph ballast tub for use with closed-circuit TV... 20

20 Photograph taken during Dive No. 83, 13 November 1961...21

21 Photograph taken during Dive No. 83, 13 November 1961...21 


\section{BACKGROUND}

The bathyscaph was purchased by the U. S. Navy in 1958 , and it has since been considered to be an operational vehicle capable of allowing its passengers to view any portion of the deep ocean. This, however, is not strictly accurate. In order to insure that the scientist will be able to make useful visual observations on every dive, it is necessary to have a reliable lighting system.

At the time of its purchase, the bathyscaph utilized a highvoltage, mercury-vapor lamp system. The lamps used were specially manufactured for the bathyscaph by Phillips in Belgium (fig. 1). Whereas the bulbs worked well in many cases, they were not uniform in reliability. Some failed on first trial and others failed after only short-duration use.

There were apparently several causes for the failures, but the most frequent failure was attributed to inability of the bulb to withstand sudden changes in temperature. Since the temperature in the deep oceans is near the freezing point, the bulb casing was required to withstand a sudden transition from a low ambient temperature to a high bulb temperature, then again back to near $0^{\circ} \mathrm{C}$ when it was extinguished.

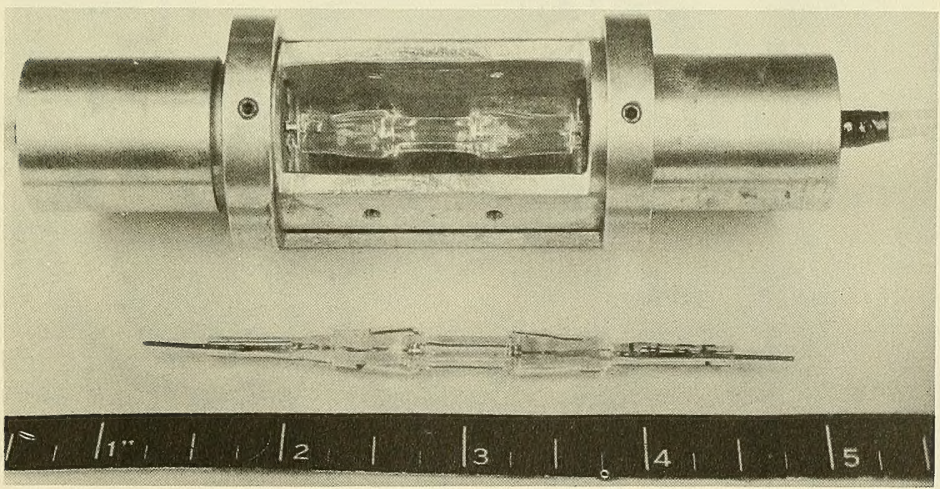

Figure 1. Mercury vapor lamp employed in the original lighting system on the bathyscaph. The steel casing was used to provide a solid mount and to hold the reflector. 
Several system failures were attributed to breakdown of wire and connector insulations under the high voltage imposed upon them. Replacement was impracticable because of the expense and long lead time involved in foreign purchase transactions. The construction of the bulb, which demanded that each unit be individually mounted, required very careful hand-wiring and insulating.

Figure 2 shows a pair of lamps and mounts installed on the bathyscaph. The only U. S. - made bulb with characteristics similar to those of the Belgian type was the General Electric AH-6 (fig. 3), which is a liquid-mercury bulb requiring an even higher voltage. Although one AH-6 was used success fully on two dives, it was apparently only by chance that

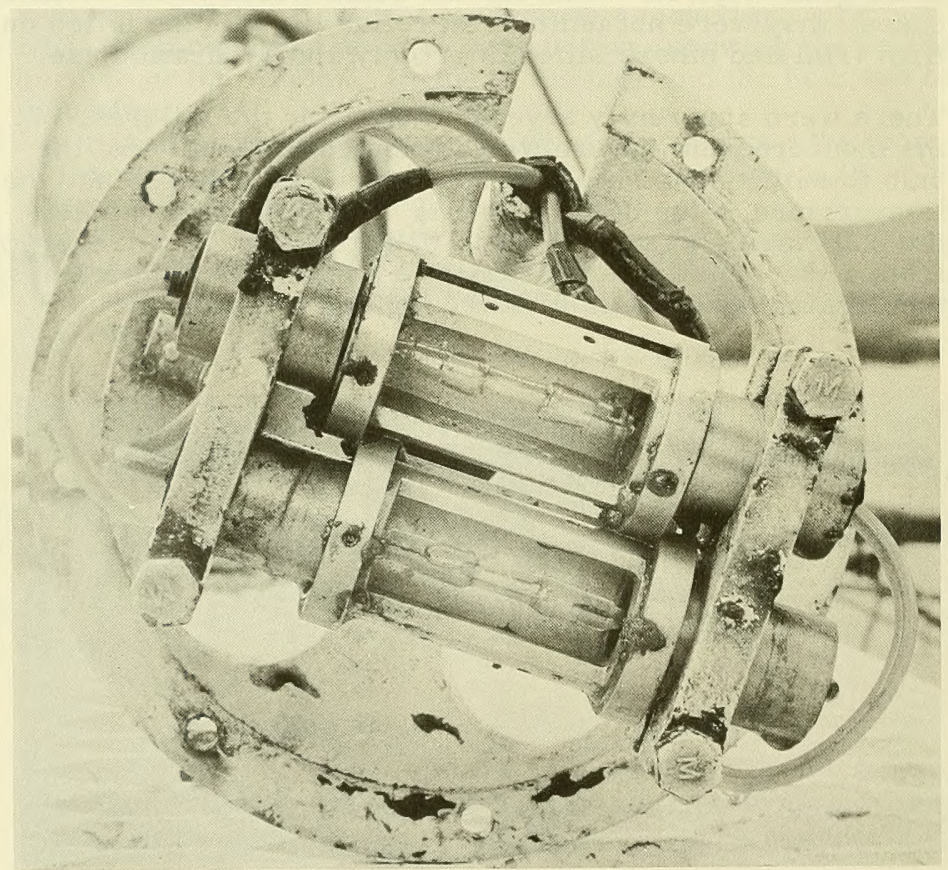

Figure 2. Mercury vapor lamps of original lighting system shown mounted in tandem as originally used on bathyscaph. 


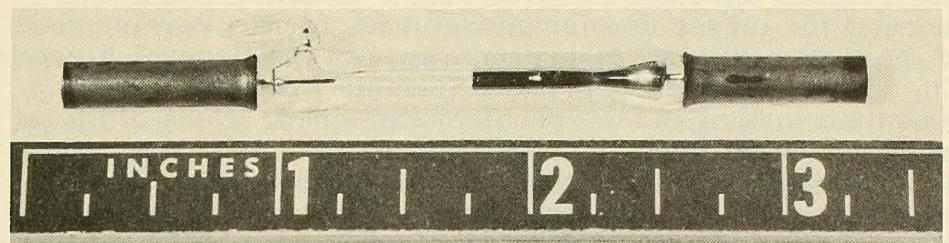

Figure 3. General Electric AH-6 lamp that was unsuccessfully attempted as a substitute for original mercury vapor lamp.

ignition was obtained at the lower voltage used since none of the other General Electric bulbs tested achieved ignition when installed in the bathyscaph lighting system.

Such difficulties had prevented the full visual and photographic observations of which the bathyscaph is capable. These advantages were not available during the 1958-59 dive series off California nor during Projects NEKTON I and NEKTON II.

To achieve the full visual and photographic potential of the bathyscaph, a lighting development program was therefore initiated in August 1960. This report covers the progress of that program to date.

\section{DEVELOPMENT CONSIDERATIONS *}

The most important developmental factor of the lamp is its ability to function efficiently in the harsh conditions imposed by the deep-sea environment. Since pressure in the deep ocean reaches 16,000 psi, an acceptable safety margin for the lamp would be its capacity to withstand 20,000 psi. In addition, the temperature often approaches $0^{\circ} \mathrm{C}$. Various methods of overcoming adverse environmental features of the deep sea will be discussed for each of the lamps tested.

* (See NEL Report 1096, Technological and Operational Aspects of the Operations of the Bathyscaph TRIESTE 19581961 , by LT D. Walsh, USN, in press) 
The original development plan was to contract with one or more of the larger lamp manufacturers for the development of the light sources. Representatives of the General Electric Co., Westinghouse Corp., and Sylvania Products were consulted in turn and the problem explained. None of the potential contractors had a suitable lamp nor did they wish to undertake the development of one, primarily because of small demand. In addition to the companies, the Bureau of Ships, Code 644, was contacted. The Bureau indicated that it could not help in certain specific areas, particularly with regard to the extreme pressure requirement. The Bureau did, however, provide one lamp casing for shallower depths. The tests conducted on the BUSHIPS casing are described in a subsequent section.

During the course of the investigations, PEK Laboratories, Palo Alto, California, indicated its willingness to undertake the development of a lamp to meet the bathyscaph requirements. While the lamp under development by this contractor shows promise, the company itself is too small to carry out a rapid program. Although two models have thus far been tested, the lamp is still some distance from completion.

The delay involved in awaiting production of a suitable lamp by PEK Laboratories or some other supplier led to development of an interim lamp at the Navy Electronics Laboratory. The development program and the resulting equipment are described in the following section.

\section{NEL (AKIN) LAMP}

Since PEK Laboratories in its lamp development program was approaching the pressure problem by making the lamp envelope itself strong enough to resist the pressure of the deep ocean, it was decided to attack the problem at NEL from another angle. By using a pressure-resistant casing, a lamp that would be readily available as an "off-the-shelf" item could be used.

The first step then was to find a suitable lamp and design a pressure casing around it. The most promising was a relatively new 150-watt, 24-volt incandescent lamp developed by the General Electric Co., Cleveland, Ohio. The lamp uses a mixture of iodine and argon gases which causes the tungsten, which evaporates from the filament, to redeposit 
on the filament rather than on the bulb wall, as with a normal incandescent lamp. This results in very nearly 100 per cent lumen maintenance and greatly increased lamp efficiency.

Maintenance of the iodine cycle, $W+2 I=W I_{2}$, depends upon the maintenance of a $3000^{\circ} \mathrm{C}$ filament temperature and a wall temperature of at least $600^{\circ} \mathrm{C}$. This high-temperature requirement is a definite advantage in a bulb that must be sealed in a heavy casing where there is no ventilation, since it is very difficult to radiate the heat through the heavy pressure casing as would be required with a normal incandescent lamp. This factor, coupled with the high luminous efficiency of the bulb, made it a natural choice for this application.

The first item in the development of the pressure casing was the window. As with nearly all "window" applications for the bathyscaph, Plexiglas was selected as the best material. While quartz, which is commonly used in pressure applications, might seem to be the logical choice, it has a tendency to fail because of even very minor flaws or scratches. A long-continuing program of tests on Plexiglas, beginning with Prof. Auguste Piccard's tests on the Plexiglas windows used in the bathyscaph, have shown that this material can be used safely in all pressure applications provided certain design criteria are followed. Plexiglas also has the great advantage of equalizing its own stresses under pressure. A scratch, which on the face of a quartz window would undoubtedly cause failure under pressure, would do nothing more than slightly retard the transmission of light in Plexiglas.

The first test casing was designed and constructed of steel. In the design of this case, a fine mesh brass screen was used between the lamp and the Plexiglas. Its purpose was to carry the heat generated by the lamp to the walls of the casing. This prevented the Plexiglas from flowing under the high temperature imposed upon it by the lamp. The casing worked well under full ocean pressure; however, the fine mesh screen cut down the light transmission. It was therefore believed that under conditions of long-duration use, the heat would not be carried away sufficiently to prevent the plastic from flowing.

The second case was designed with a water barrier between the lamp and the Plexiglas. This water barrier was main-, tained by a piece of optical glass (fig. 4). The "production" model casing that was finally selected utilized the water screen, but was constructed of aluminum instead of steel. 
This change was made primarily because of the ease with which aluminum can be machined. There was also the probable necessity for SCUBA divers to change the lamps under water. The much lighter aluminum construction would permit ease of replacement by such divers.

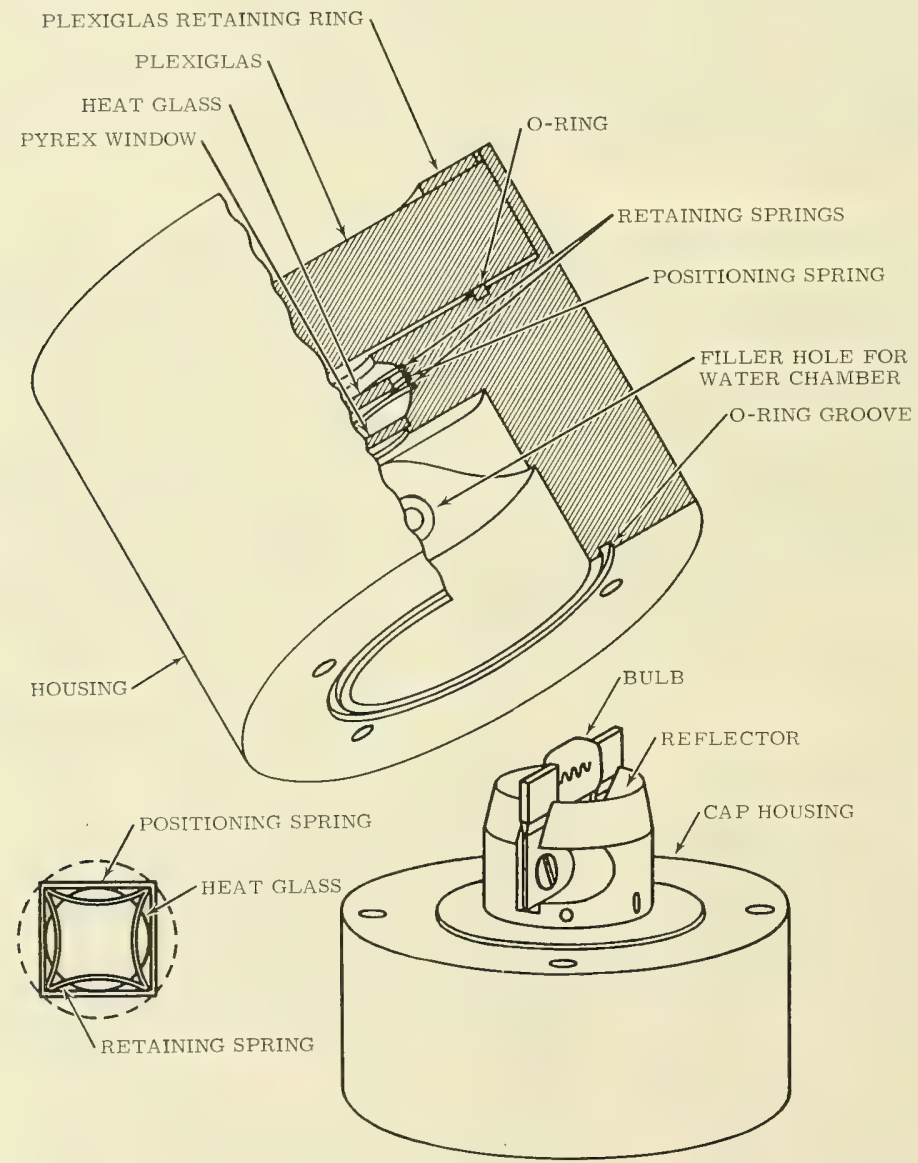

Figure 4. Construction details of NEL deep submergence lamp. 
The finalized form of the lamp may be seen in figures 5 and 6 , and the components in figures 7 and 8 . This lamp was tested at 16,000 psi for 21 hours and operated satisfactorily. It was then placed under a pressure of 20,000 psi, which caused failure after 60 minutes. Figures 9 and 10 show the test lamp after removal from the pressure chamber.

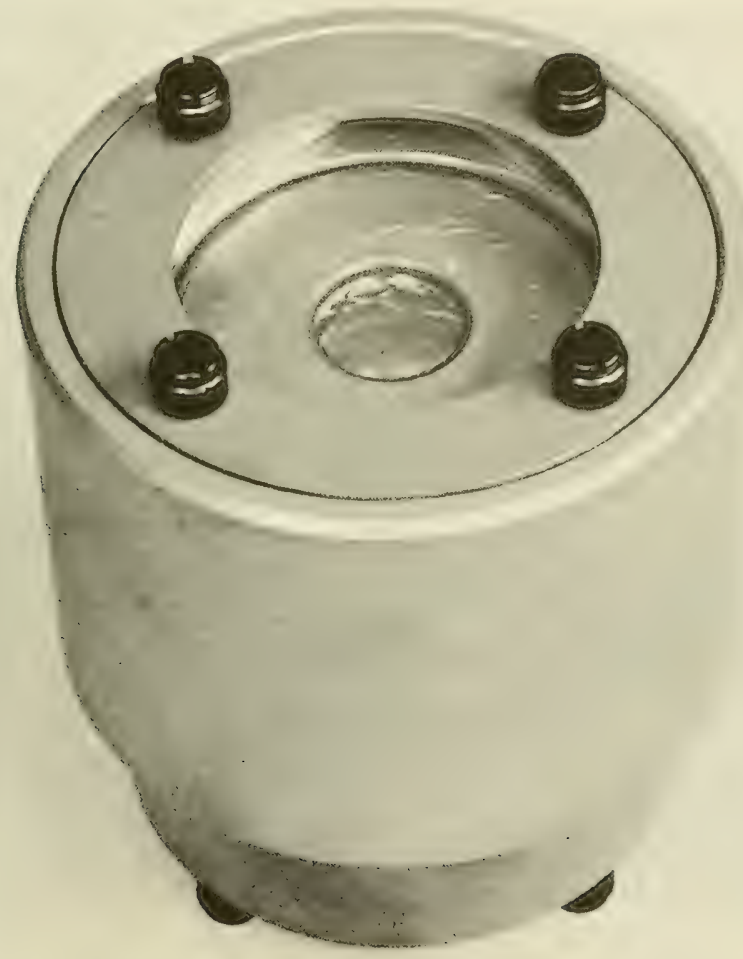

Figure 5. Oblique view of assembled NEL deep submergence lamp. 


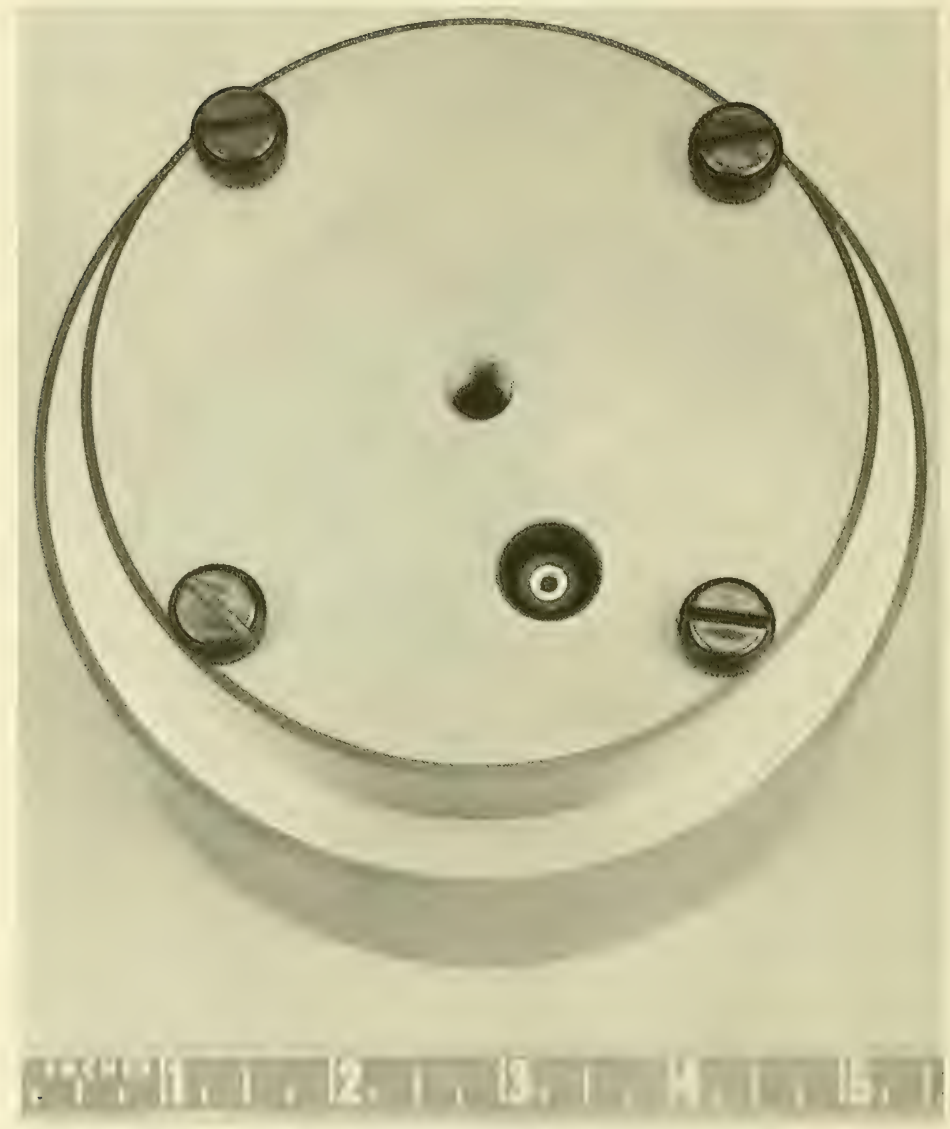

Figure 6. Top view of NEL lamp showing single mounting hole and recessed Joy plug for +24 vdc connection. 


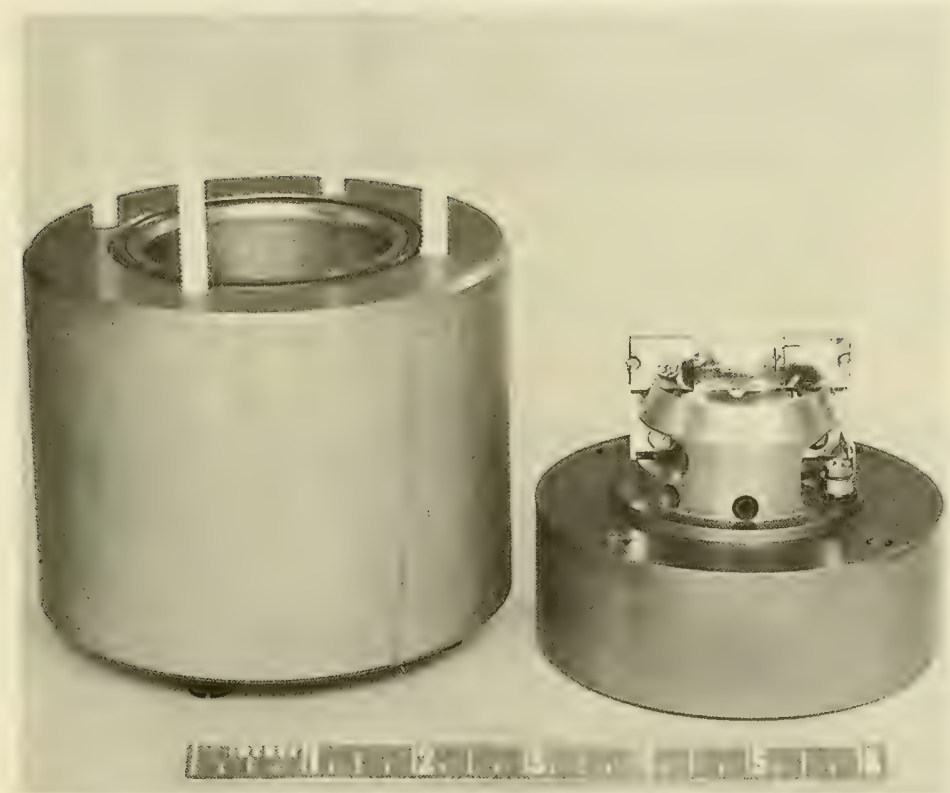

Figure 7. NEL lamp with bulb, bulb mount, and back removed. 


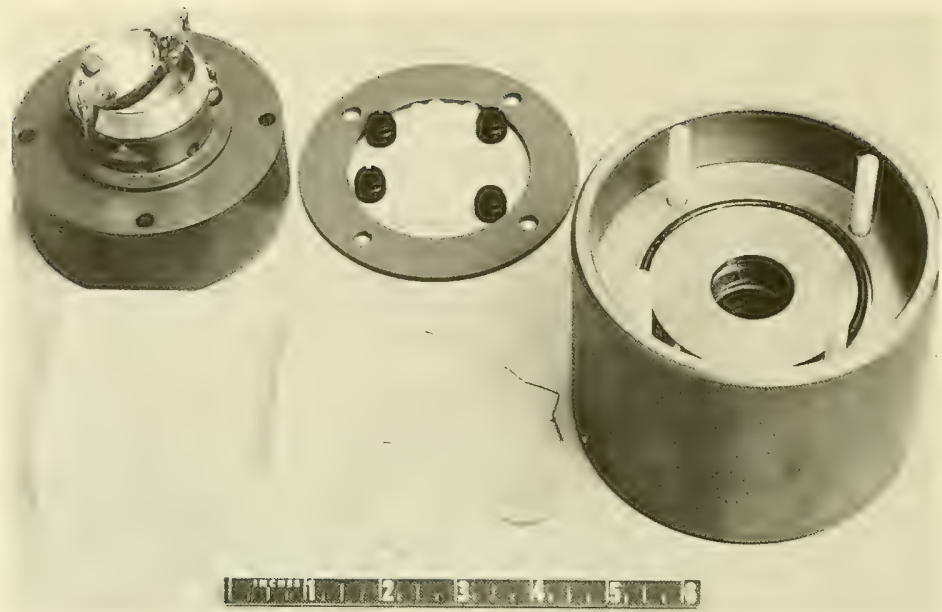

Figure 8 . Same as figure 7 with Plexiglas window and heat shield removed and showing recessed window mounting.

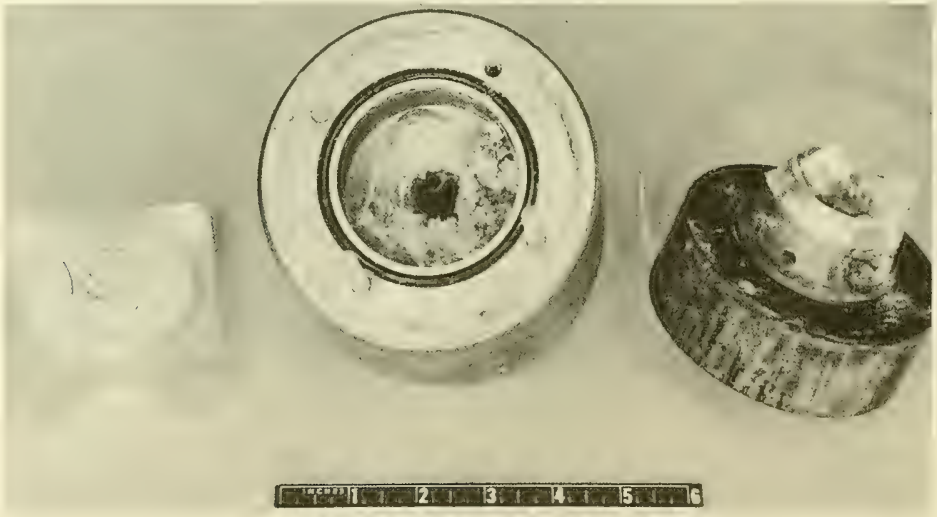

Figure 9. NEL lamp casing, tested to destruction, showing the inside surface of the window, inside of casing, and the bulb and bulb mounting. 


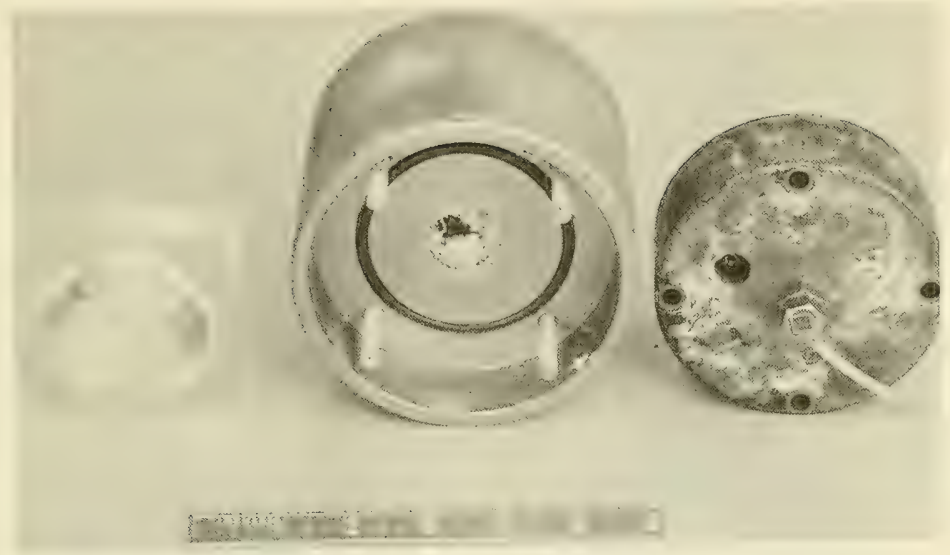

Figure 10. Same lamp casing showing outside of the window, the front of the casing, and the back of the mounting plate.

\section{EDGERTON LAMP}

During the course of the investigation and development just described, Dr. Harold E. Edgerton of Edgerton, Germeshausen, and Grier was contacted and indicated that he could construct a lamp that would be suitable for use with the bathyscaph. An order for six lamps was placed with Edgerton, Germeshausen, and Grier. The delivery time, however, was not favorable, and the indicated life of these lamps was short compared to that desired.

The Edgerton lamp (fig. 11 and 12) utilizes a pyrex casing in a tubular form. Mounted inside the tubular casing in an inverted position is a 300-watt projection lamp. Whereas this lamp was designed to burn at 28 volts, the 24 volts supplied by the bathyscaph power supply causes the lamp filament to burn brightly enough to furnish adequate illumination for visual observations and photography providing a high-speed film is used. The 300-watt projection bulbs designed for $24 \mathrm{v}$ dc have been ordered. It is expected that this will improve the lamp somewhat although the bulb life will probably be shorter. 

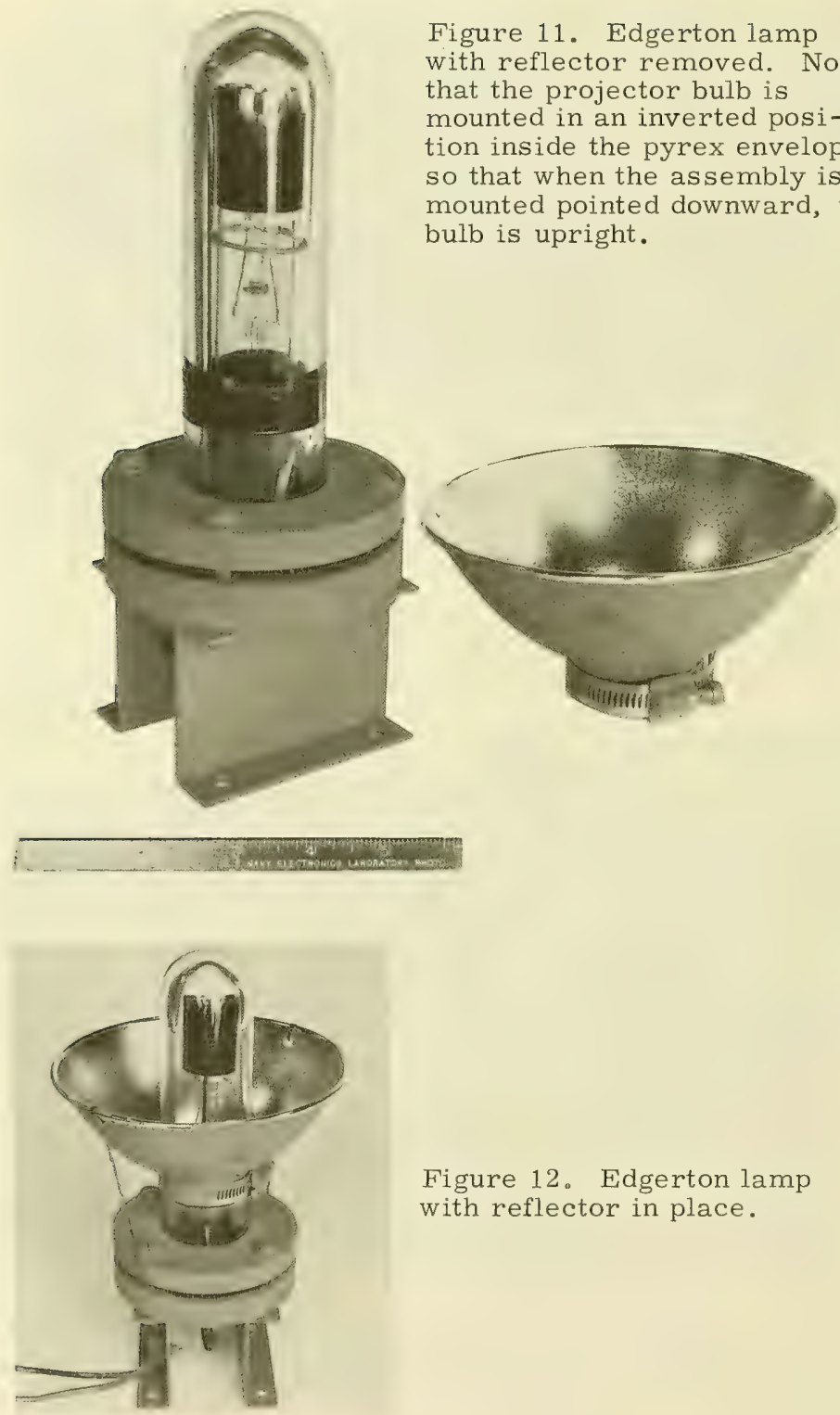

Figure 12. Edgerton lamp with reflector in place. 


\section{BUSHIPS LAMP CASING}

The casing provided by the Bureau of Ships for testing is a standard stock Navy item used in submarines as a navigation lamp. The highest pressure to which it had been subjected by the Bureau was 3000 psi. This pressure had not caused failure of the casing, and it was therefore considered adequate for use on present-day submarines. Two of the casings were tested in the bathyscaph pressure facility. The first failed at $4500 \mathrm{psi}$, the second at $4000 \mathrm{psi}$.

Thetests indicated that, including a safety factor of 25 per cent, these lamp casings would be suitable for use to depths of 6500 feet. At the time the casings were tested, the planned dive schedule for the bathyscaph included a large number of dives to greater depths, and the immediate problem was the development of a lamp for these greater depths. The BUSHIPS casing was therefore set aside for a later diving program during which shallower dives might require large amounts of illumination and the casings could be utilized. Construction of the casings may be seen in figure 13. Figure 14 shows components of two of these lamp casings after testing to destruction.
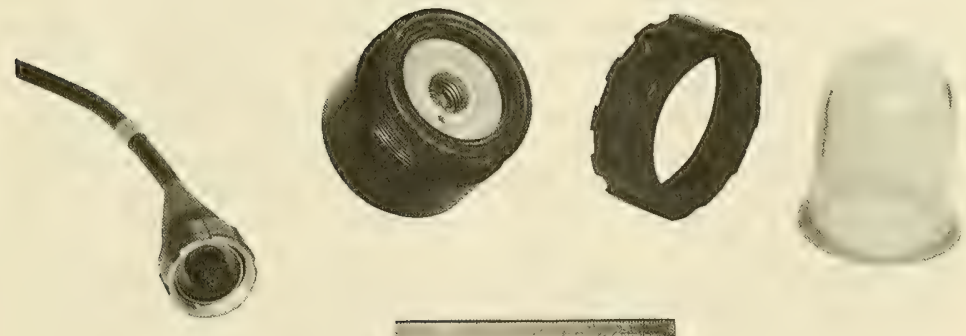

Figure 13. Disassembled BUSHIPS lamp casing. 


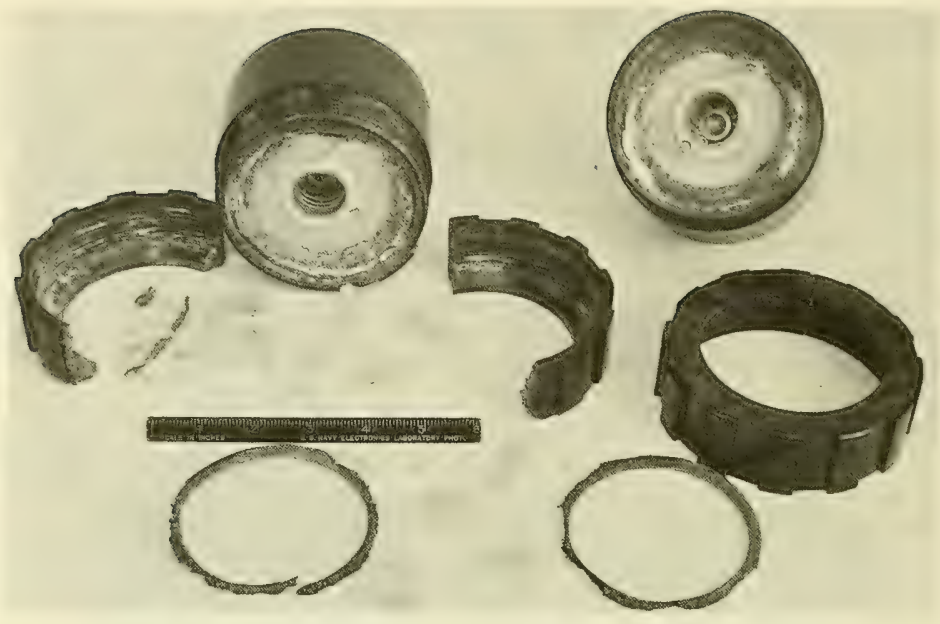

Figure 14. Components of two BUSHIPS lamp casings after testing to destruction.

\section{PEK LAMP}

The specifications for the lamp to be developed by PEK Laboratories required (a) that it was to be a 500 -watt lamp; (b) the casing of the lamp itself was to withstand 20,000pounds-per-square-inch static pressure; and (3) the lamp was to burn at 3200 degrees $K$. The contractor indicated at first that the lamp would be in production quantities in time to meet the operational commitments of the bathyscaph; however, because of difficulties in obtaining the necessary quartz for the pressure-resistant bulb envelope, this schedule could not be met.

The first test lamp was received in February 1961 and burned satisfactorily in water, but under even relatively low pressures it was found to leak. When removed from the pressure tank small amounts of the fluid from the tank had entered the envelope. The envelope was then reworked and tested in the pressure chamber at 20,000 psi. After burning for 5 minutes, the bulb ceased drawing current. 
Upon removal from the pressure tank, the bulb was found to be intact, but a small amount of fluid had passed into it. The second test bulb (fig. 15) sustained damage that precluded operating tests, but a series of structural tests of the bulb were conducted and the envelope was found to leak at 16,000 psi.

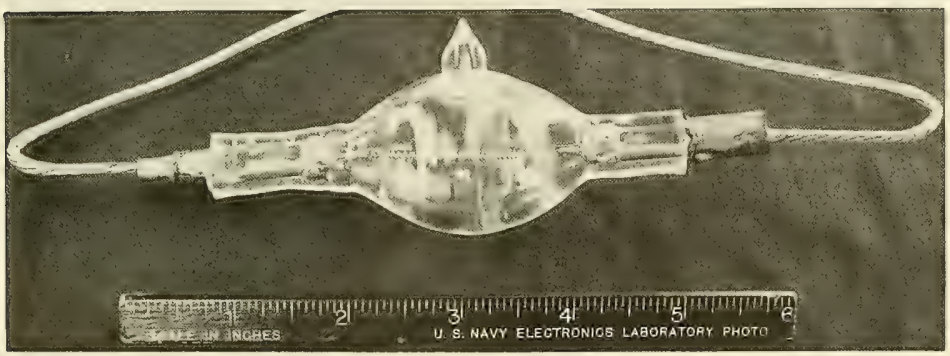

Figure 15. PEK Laboratories 500-watt, 24-vdc incandescent lamp, Model No. 3.

\section{RESULTS AND DISCUSSION}

By using a combination of the NEL lamp with its reliability, long life, and ease of replacement, and the Edgerton lamps with their satisfactory areal lighting, some fairly good results, both visually and photographically, have been obtained. Figures 16 through 19 show the various mountings of these lamps on the bathyscaph.

It will be necessary to continue the lighting development program until lights are developed that provide the proper color temperature to produce the best possible photographic results. After over a year of effort, it is believed that this program is entirely feasible; however, a great deal of further effort will be necessary before the objectives are attained.

It is expected that supplementary reports will be issued as further results are obtained during the course of the program. 


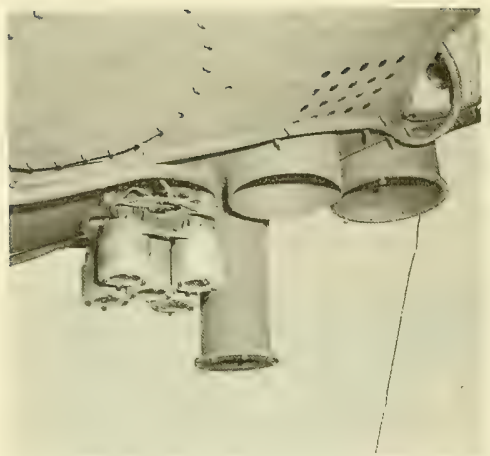

Figure 16. Side view of NEL lamp cluster under the bow of the bathyscaph.

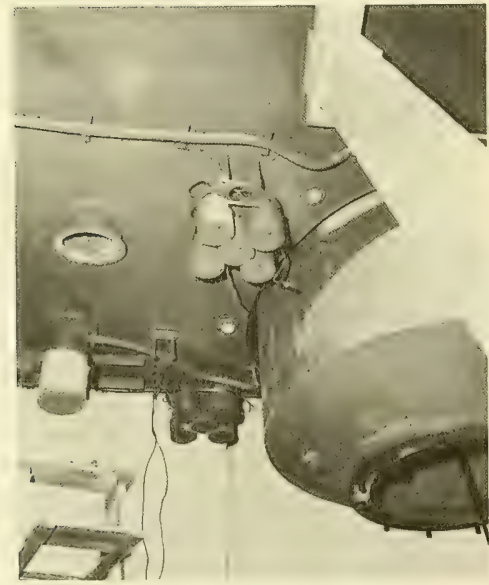

Figure 18. Two five-lamp clusters of NEL lamps, amidships.

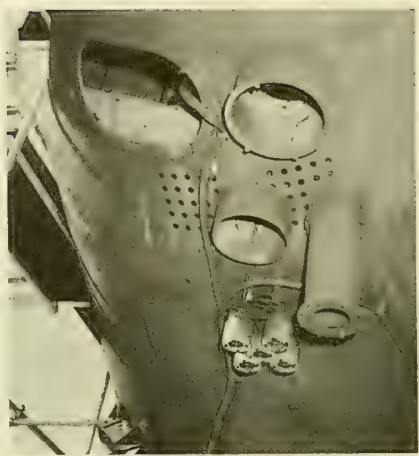

Figure 17. Bottom view of bow lamp cluster.

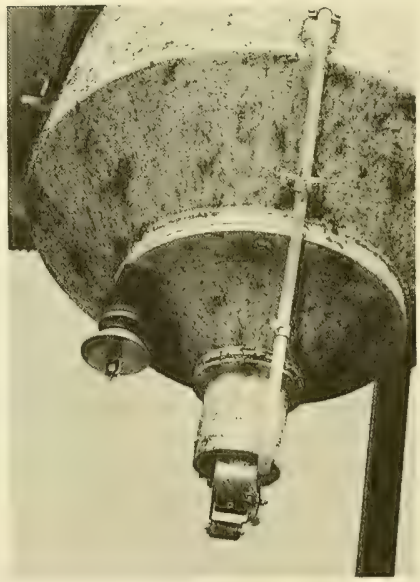

Figure 19. Edgerton lamp mounted on bathyscaph ballast tube for use with closed-circuit TV. 


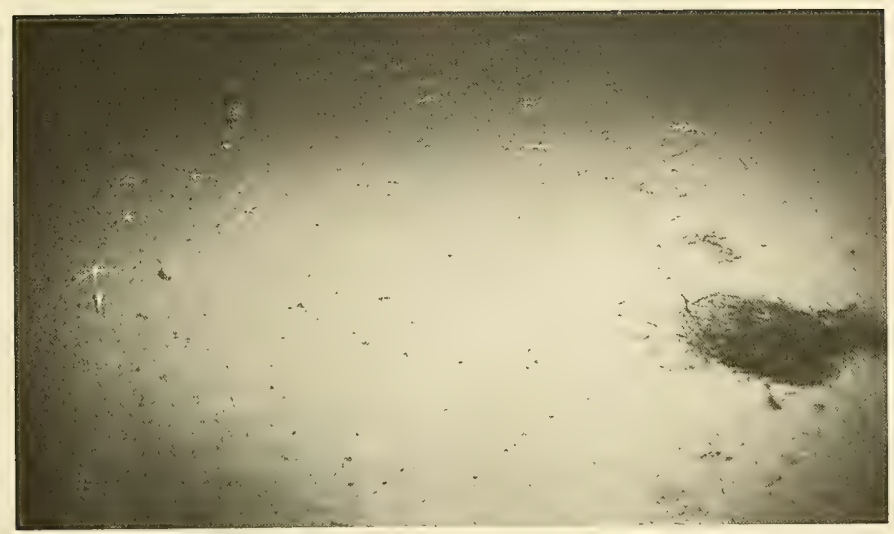

Figure 20. Photograph taken during Dive No. 83, 13 November 1961.

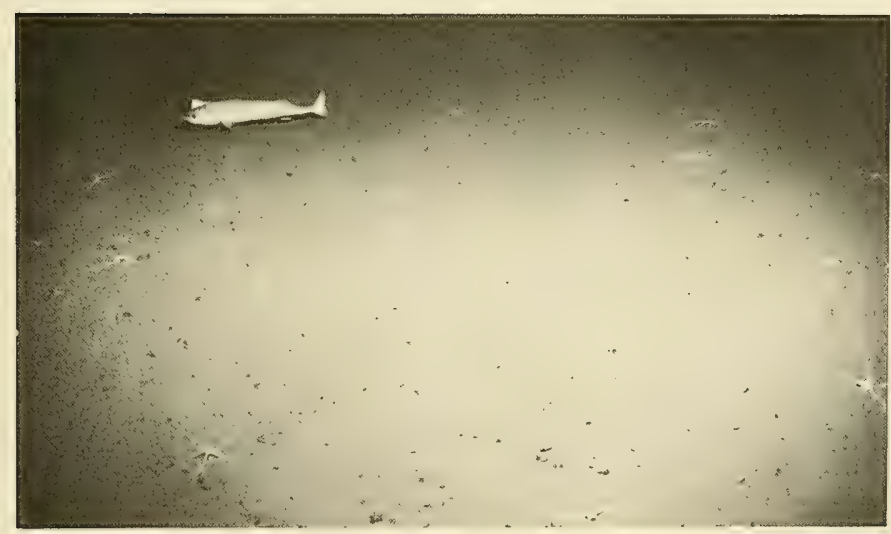

Figure 21. Photograph taken during Dive No. 83, 13 November 1961 . 


\section{RECOMMENDATIONS}

1. Continue the program to improve the presently operational lighting system on the bathyscaph.

2. Complete development of a lamp that meets all of the requirements stated above. 




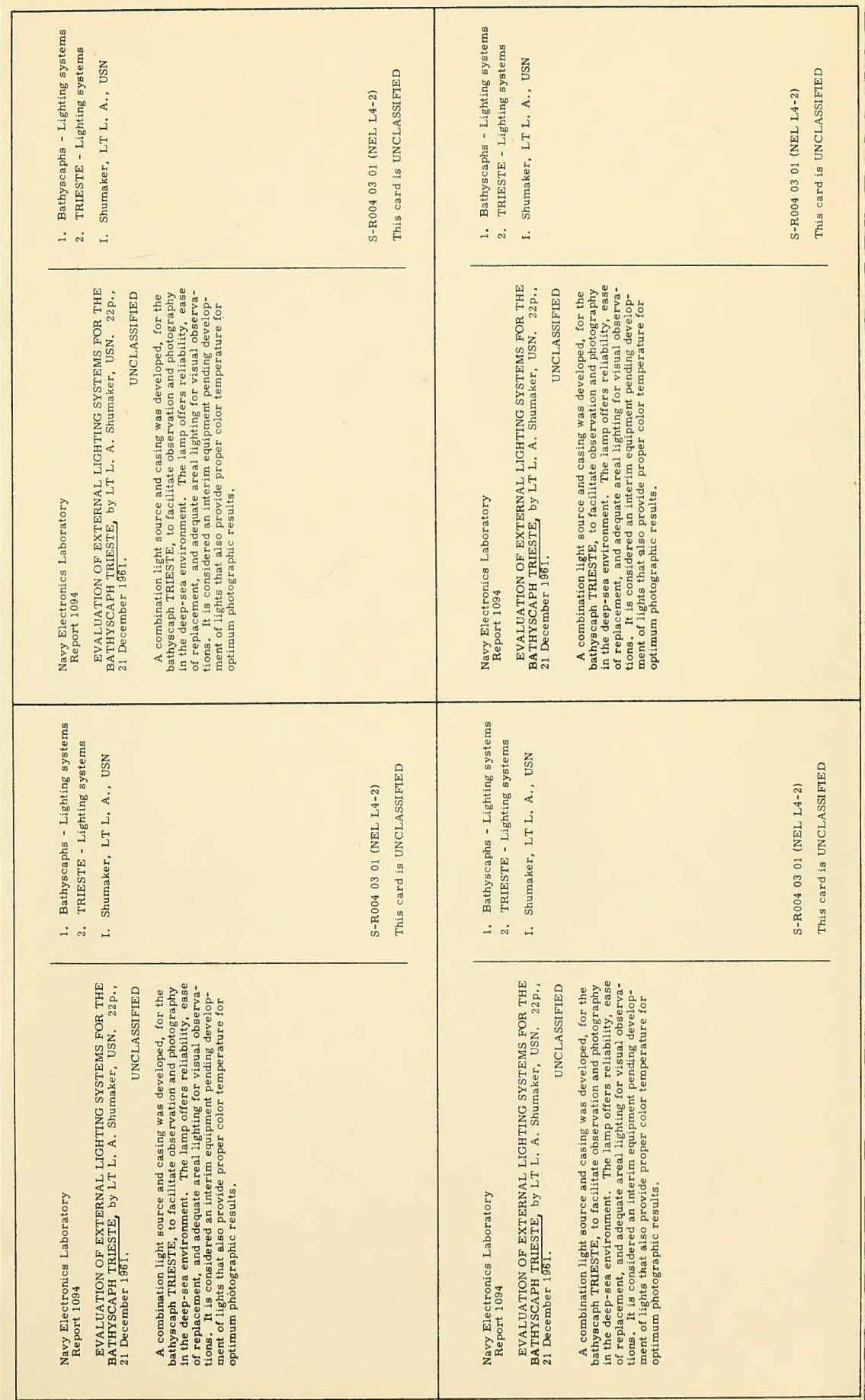


Bureau of Ships

Code 320

Code 335 Code 360

Code 688

Bureau of Naval Weapons

$D L I=3 \quad D L I-31$ (2) RUDC-2

RUDC-11 FAME-3

Bureau of Yards and Docks

Chief of Naval Personnel

Pers $11 B$

Chlef of Naval Operations

$0 p-07 T$ op-73 (2) $0 p-03 E G$

Chief of Naval Reaearch

Code 416 Code 418 Code 463

Code 466

Commander in Chief, Pac Flt

Commander in Chief, Lant Flt

Commander operational Test \& Eval. For, Lant Flt Pac Proj

Conmander, Crutser-Destroyer For, Pac Flt

Commander Traintng Command, Pac Flt

Commander Submarine Development Group TWO

Commander Service For, Pac Flt, Library

Commander Key West Teat \& Eval. Det.

Naval Atr Development Center, Library Aeronautical Instrument $L a b$.

Naval Mtssile Center

Tech. Library

Naval Ordnance Laboratory, Ltbrary (2)

Naval ordnance Test Station, Pasadena Annex Library

Naval Ordnance Test Station, China Lake Code 753

Naval Radlological Defense Laboratory

David Taylor Model Bastn

Navy Mine Defense Lab., Code 712

Navy Underwater Sound Laboratory Code 1450 (3)

ASW Tactical School, Lant Flt

Naval Engineerting Bxperiment Station $L t b r a r y$

Naval Research Laboratory Code 2027 (2)

Navy Underwater Sound Reference Lab I $t$ brary

Air Development squadron ONE (VX-1)

Fleet Sonar School

Fleet $A S W$ School

Naval Medical Field Research Lab.

Office of Naval Research, Pasadena

Navy Hydrographtc office, Ltbrary

Div. of oceanography

Air Weather Service Lialson office

Naval Postgraduate School, Library (2)

Meteorology \& Oceanography Dept. (2)

Navy Repreaentative, Project IINCOLN, MIT

Assiatant SECNAV, Research \& Development

DOD, Reaearch \& Engineering, Tech. Library Committee on Sctencea

Assistant Chief of Staff, G-2, US Army, IDB (3)

Chief of Engtneers, US Army, ENGRD-MF

The Quartermaster General, US ATmy

$R$ \& $D$ Div., CBR Lialson officer

Army Rocket \& Guided Missile Agency Techntcal Ltbrary

Army TRECOM, Research Reference $D i v$.

Continental Army Command, ATDEV- 8

Beach Eroston Board, Corpo of Englneers, US Army

Atr Defense Command, ADOOA

Air Universtty, Library AUL3T-5028

Strateglc Atr Command, Operations Analyats

Atr Force Cambridge Laboratory CRREL-R

Marine Physical Laboratory, Univ. Calif.

Scripps Institution of oceanography, Untv. Caltf.
National Research Council

Committee on Undersea Warfare (2)

U. S. Coast \& Geodet $t$ c Survey

Director, $D t v$. of $T i d e$ \& Currents

U. S. Fish \& Wilditife Servtce, Pacific

oceantc Fishery Investigations, Library, Honolulu

US Fish \& Wilditfe Service, La Jolla

South Pacific Fishery Investigations

Dr. E. H. Ahlstrom

US Weather Bureau, Dr. Wexler

University of Alaska, Geophysical Institute

Brown Univers $t$ t $y$, Research Analysis Group

Universtty of California at Los Angeles, Englneering Dept.,

The Johns Hopkins University Chesapeake Bay Institute, Library

University of Miant, Marine Laboratory

New York University Meteorology \& oceanography Dept.

$A$ \& $M$ College of Texas, Dept of Oceanography

University of Texas Defense Research Laboratory

Untuersity of Washington Department of cceanography

Yale University Singham oceanographic Lab.

Lamont Geological observatory

Woods Hole oceanographic Institution Laboratory of oceanography

Vitro Corp. of America, Stluer spring Lab, Library

Columbia University, Hudson Labs.

Headquarters, U. S. Coast Guard Aerology \& oceanography Section

US Naval Academy

Civil Engineering Laboratory, L54

Office of Naval Research

Contract Admintstrator, S. B. Area

Chlcago

Boston

New York

San Franciaco

Allan Hancock Foundation

Arctic Research Laboratory

US. Geologtcal Survey

US Fish \& Wildlife Service Point Loma

Stanford

Washington, D. C. (2)

Woods Hole

Geophys :cs Research

Narragansett Marine Laboratory

Waterways Experiment Station

Navy Weather Research Factlity

Cornell Untversity, Department of Conservation

Florida State Untuersity.

oceanographic Institute

University of Hawait, Marine Lab.

Oregon State College, Dr. Burt

Rutgers University, Dr. Haskins

AWS, Scott AFB, IIIinois

General Precision Laboratory, Inc.

The Martin Company, Baltimore

Sylvanta Electrtc Defense Lab., Dr. Beard

Bureau of Comm. Fisheries, Bio. Lab.

Wash D. C.

Point Loma sta. 